\title{
Higher Education Levels, Firms' Outside Options and the Wage Structure
}

\author{
Åsa Rosén*and Etienne Wasmer ${ }^{\dagger}$
}

December, $2001^{\ddagger}$

\begin{abstract}
We analyze the consequences of an increase in the supply of highly educated workers on relative and real wages in a search model where wages are set by Nash-bargaining. The key insight is that an increase in the supply of highly educated workers improves the firms' outside option. As a consequence, the real wage of all workers decreases in the short-run. Since this decline is more pronounced for less educated workers, wage inequality increases. In the long-run a better educated work force induces firms to invest more in physical capital. Wage inequality and real wages of highly educated workers increase while real wages of less educated workers may decrease. These results are consistent with the U.S. experience in the 70s and 80s. Based upon differences in legal employment protection we also provide an explanation for the diverging evolution of real and relative wages in Continental Europe.
\end{abstract}

Key Words: Wage Inequality, Matching, Creation Costs, Firing Costs.

JEL Classification: J31

${ }^{*}$ Corresponding author. Address: Swedish Institute for Social Research, Stockholm University, S106-91, Stockholm, Sweden. E-mail: Asa.Rosen@sofi.su.se

${ }^{\dagger}$ Address: ECARES, Université Libre de Bruxelles, CP 114, 50 Av. F. Roosevelt, 1050 Ixelles, Bruxelles. E-mail: ewasmer@ulb.ac.be

${ }^{\ddagger}$ We thank Peter Fredriksson, Fabien Postel-Vinay, and seminar participants at the European Economic Association Meeting in Santiago de Compostella, Göteborg University, the Norwegian School of Management (BI), Swedish Institute for Social Research, The Research Institute of Industrial Economics, Uppsala University, UCL workshop in Matagne-la-Petite, IZA in Bonn, and Uppsala University. Financial support from the Swedish Council for Research in the Humanities and Social Sciences and Jan Wallaner and Tom Hedelius' Foundation (Rosén) is gratefully acknowledged. 


\section{Introduction}

During the 70s and 80s most OECD countries experienced an increase in the supply of educated workers. ${ }^{1}$ Despite this increase, the education premium rose substantially in the U.S. during this period. ${ }^{2}$ Empirical studies on the education premium in Europe offer a different and mixed picture: In general, a substantial increase in the education premium is documented for the U.K., while the increase is smaller or even inexistent in many other European countries, such as France, Germany, and Sweden. ${ }^{3}$ Common explanations for the U.S. experience are skill-biased shifts in the labor demand (e.g., Bound and Johnson (1992) and Berman et al. (1994)), increased trade with developing countries (e.g., Wood (1994)), and institutional changes, such as changes in the minimum wage legislation or the decline in unionization (Di Nardo et. al. (1996) and Lee (1999)). As regards real wages, the U.S. and the European experience also differ. Real wages of high paid workers increased in both Europe and the U.S. during the 80s. By contrast, real wages of low paid workers increased in most European countries, but decreased in the United States. ${ }^{4}$

The present paper makes three contributions. First, it offers a new explanation for why an increase in the supply of highly educated workers may lead to an increase in the education premium. Second, it shows that such an increase may raise real wages of highly educated workers but lower real wages of less educated workers. These two results match the U.S. experience of increased education premium and lower real wage for the less educated workers. Third, by introducing firing costs which are thought as higher in Europe than in the U.S., we can also account for the different evolution of relative and real wages in Europe.

The key determinant of wage inequality in our sequential search model is the firm's threat point in the wage bargaining. The equilibrium wage is equal to a fraction of the worker's marginal product less the firm's threat point in bargaining. An increase in the firm's threat point reduces real wages for all workers by the same amount. Hence, real wages of less educated (productive) workers decrease more and wage inequality increases. Based on this mechanism, we explore the short and long run impact of an increase in the supply of highly

\footnotetext{
${ }^{1}$ See e.g., Katz et al. (1995), Nickell and Bell (1995), Abraham and Houseman (1995), and Card et al. (1996).

${ }^{2}$ See e.g., Katz and Murphy (1992), Juhn et al. (1993), and Levy and Murname (1992).

${ }^{3}$ See Davis (1992), Nickell and Bell (1995), Abraham and Houseman (1995), Card, et al. (1996), Gottschalk (1997), and Machin and Van Reenen (1998).

${ }^{4}$ OECD Job Study (1994, Chapter 1)
} 
educated workers in the absence of firing costs as well as in the presence of firing costs.

In the absence of firing cost the firms' threat point is simply their outside option, i.e. the value of a vacancy. In the short-run where the number of firms and the amount of physical capital is given, an improvement in the quality of the labor force raises the value of a vacancy. This increases the firms' threat point which in turn increases wage inequality.

In the long run there is free entry of firms, and firms choose the amount of physical capital prior to being matched with a worker. When the firm can redeploy (even a small part of) the physical capital if a match breaks down during bargaining, the firm's threat point in the bargaining corresponds to the positive value of the capital that the firm can redeploy. Under the assumption of complementarity in production between physical and human capital, firms invest more in physical capital after an increase in the supply of highly educated workers. The larger capital stock increases the firms' threat point and hence leads, ceteris paribus, to lower wages and to more wage inequality. There is, however a counterveiling effect: More investments in physical capital also raises the workers' productivity, which increases wages. The outside option effect always dominates for workers with low levels of education and their real wages decrease. In contrast, the productivity effect may exceed the outside option effect for highly educated workers, and consequently their real wages may increase.

Firing costs which are not transfers to workers, e.g. administrative costs, lower the firms' threat point in wage bargaining. When firing costs are proportional to the average productivity in the economy, an increase in the education level of workers increases both the value of a vacancy and the firms' firing costs. The net impact on the firms' threat point depends on the magnitude of the firing costs. When firing costs are low, the net effect of an increase in the supply of highly educated workers is positive, and wage inequality increases. Otherwise, the net effect on the firms' threat point becomes smaller and may even be negative. Consequently, an increase in the supply of highly educated workers attenuates the trend to more wage inequality or may even reverse it. Firing costs also affect how real wages change in response to an increase of highly educated workers. As above, the threat point may decrease when firing costs are large, and the wages of all workers increase. When firing costs depend on the cause of separation a novel result obtains: Firing costs associated with separation during bargaining increase real wages, while firing costs associated with exogenous job destruction reduce real wages.

Several recent papers show that an increase in the supply of highly educated workers 
may increase wage differentials. In Caroli and Van Reenen (1999) and Beaudry and Green (1998), changes in wage inequality are driven by organizational changes. In Acemoglu (1999), Duranton (1997), and Rioux (1995), an increase in the supply of skilled workers leads to a higher degree of labor market segregation which increases inequality and lowers the wages of workers with low education levels. Machin and Manning (1997) and Albrecht and Vroman (1999) examine wage inequality in a model where some workers cannot perform all jobs. An increase in the supply of highly educated workers induces some firms to switch from the low education to the high education segment. This improves the prospects for highly educated workers to such an extent that their relative wage increases. In the absence of firing costs, our model generates similar results but it relies on a different mechanism than the above models. An increase in the supply of highly educated worker affects real and relative wages because it changes the firm's threat point in wage bargaining.

Like the present paper, Acemoglu (1997) also establishes a link between the firms' outside option and wage inequality. Studying the evolution of income inequality, he finds that wage inequality rises at high levels of inequality but diminishes at low levels. Contrary to the present paper, he does not examine the impact of an increase in the supply of highly educated workers on real and relative wages.

Finally, none of the above papers considers firing costs, which are key in our model to explaining the diverging evolution of wage inequality in the U.S. and Europe. Previous papers that analyze firing costs focus on the relationship between firing costs and (un-)employment levels or unemployment duration. ${ }^{5}$ An exception is Mortensen and Pissarides (1999b). Their analysis differs from the present one in several respects. In particular, they consider how changes in wage inequality following a skilled biased technical change varies with the level of firing costs.

The paper is organized as follows. Section 2 presents the basic model. Section 3 analyses the effect of an increase in the supply of highly educated workers on wage inequality and real wages in the absence of firing costs. Section 4 examines the model with firing costs. Section 5 generalizes the model and discusses the robustness of our results. Section 6 concludes.

\footnotetext{
${ }^{5}$ See e.g., Blanchard (1997), Burda (1992), Bertola (1990), and Saint-Paul (1995).
} 


\section{The model}

\subsection{Workers and firms}

Our model extends the standard continuous time search model with sequential search and wage determination by Nash-bargaining, as in e.g., Pissarides (2000). Workers are infinitely lived, risk neutral, and have a discount rate $r$. They differ in their educational level $h$. The education level is distributed on the support $[\underline{h}, \bar{h}]$ with density function $f(h)$ and distribution function $F(h)$.

Firms are identical, risk-neutral, and have the same discount rate $r$ as the workers. A production unit consists of one worker with human capital $h$ and $k$ units of physical capital and generates an output $y=h^{\lambda} k^{1-\lambda}$. In the short run, the number of firms and the amount of physical capital are given. In the long run there is free entry, and firms choose the level of physical capital. Following Acemoglu (1996, 1997, 1999), firms make their investments in physical capital (e.g., buildings, equipment) before being matched with a worker.

Assumption 1 When a firm and a worker separate, the entire physical capital can be redeployed in the next match.

This Assumption simplifies the analysis but is unnecessarily restrictive as shown in section 5. To obtain our results it suffices that the firm can redeploy part of the capital $k$ if that firm and its worker were to separate during bargaining. This ensures that the firm's threat point in bargaining depends in the long run on the physical capital.

We define the aggregate education level in the economy by $E\left(h^{\lambda}\right)=\int_{\underline{h}}^{\bar{h}} h^{\lambda} f(h) d h$ and denote it by $\varepsilon=E\left(h^{\lambda}\right)$. If a distribution $F_{0}$ first order stochastically dominates a distribution $F_{1}$, i.e., $F_{0}(h)>F_{1}(h)$ for all $h$, then $\varepsilon$ is lower for the distribution $F_{0}$ than for $F_{1}$.

\subsection{Matching}

Workers are either unemployed or employed, and jobs are either vacant or occupied. Only unemployed workers and vacant jobs engage in search. Let $u$ denote the number of unemployed workers, $v$ the number of vacancies, and $\theta=v / u$ the tightness of the labor market. Unemployed workers and vacant jobs match randomly according to a constant returns to scale matching function $M(u, v)$. Hence, the rate at which a vacant job is matched with an unemployed worker is $M(u, v) / v=q(\theta)$, and the rate at which an unemployed workers is matched with a vacant job is $M(u, v) / u=\theta q(\theta)$. As is commonly assumed, the matching 
function satisfies $q^{\prime}(\theta)<0$ and $\frac{d \theta q(\theta)}{d \theta}=\theta q^{\prime}(\theta)+q(\theta)>0$. These restrictions imply that a tighter labor market makes it more difficult for firms to fill a vacancy but easier for workers to find a job. Employed workers separate from jobs at an exogenous rate $\delta$, and the workers' income flow while unemployed is normalized to zero.

Since the value of a vacancy may in equilibrium exceed zero, firms may not want to employ all workers at a wage that the workers accept. We abstract from issues of employability of workers with low education levels and focus on wage inequality. ${ }^{6}$

Assumption 2: All matches result in employment.

This is tantamount to assuming that there exist a positive wage for a worker with human capital $\underline{h}$, at which firms prefer to hire him relative to keeping the position vacant. In Appendix A we derive the restrictions on the parameter values such that Assumption 2 holds in equilibrium. A sufficient condition for this to hold is that $\underline{h}$ is sufficiently large relative to $\varepsilon^{1 / \lambda}$.

\subsection{Asset values and wages}

In general asset values and wages depend on the level of physical capital. Initially, we derive the asset values and wages under the assumption that all firms have the same level of physical capital. Denote by $U_{h}$ and $W_{h}$ the present discounted income of an unemployed and employed worker with education level $h$. In steady state, $U_{h}$ satisfies

$$
r U_{h}=\theta q(\theta)\left[W_{h}-U_{h}\right]
$$

At a rate $\theta q$ an unemployed worker finds employment in which case the present discounted income increases by $W_{h}-U_{h}$. Analogously, the present discounted income of a employed worker with human capital $h$ satisfies

$$
r W_{h}=w_{h}+\delta\left[U_{h}-W_{h}\right]
$$

where $w_{h}$ denotes the wage of a worker with education level $h$.

Denote by $V$ the value of a vacancy, by $J_{h}$ the value of a position occupied by a worker with human capital $h$, and by $J^{e}$ the expected value of an occupied position. If the firm and

\footnotetext{
${ }^{6}$ The issue of changes in employability and/or in reservation wages of different groups in response to changes in the composition of the work force is studied in Acemoglu (1999), Albrecht and Vroman (1999), and Rioux (1995).
} 
the worker separate, the firm is left with the value of a vacancy. ${ }^{7}$ In steady state, $V$ and $J_{h}$ satisfy $^{8}$

$$
r V=q(\theta)\left[J^{e}-V\right]
$$

and

$$
r J_{h}=y_{h}-w_{h}+\delta\left[V-J_{h}\right]
$$

Wages are set by Nash-bargaining. The worker's (resp. firm's) bargaining power is $\beta$ (resp. $1-\beta)$, and the parties outside options $\left(U_{h}\right.$ and $\left.V\right)$ are their threat points in bargaining. Hence, the wage of a worker with education level $h$ is determined by

$$
\underset{w}{\operatorname{Max}} \Omega(w)=\left(W_{h}-U_{h}\right)^{\beta}\left(J_{h}-V\right)^{1-\beta} .
$$

Solving the maximization problem, using (4) and (2) yields

$$
w_{h}=(1-\beta) r U_{h}+\beta\left(y_{h}-r V\right)
$$

Using (1) and (2), we can solve for $r U_{h}$ as a function of $w_{h}$

$$
r U_{h}=\frac{\theta q(\theta) w_{h}}{r+\delta+\theta q(\theta)}
$$

By inserting (7) into (6) we obtain a wage equation

$$
w_{h}=\beta \frac{r+\delta+\theta q(\theta)}{r+\delta+\beta \theta q(\theta)}\left(y_{h}-r V\right) .
$$

Equation (8) shows that wages are ceteris paribus increasing in the productivity of the worker and decreasing in the firm' outside option (threat point) $V$.

\section{$3 \quad$ Wage Inequality and Real Wages}

In this section we first derive the effects of changes in the education level on relative wages in the short and in the long run. Next we examine the effects on real wages. Finally, we relate the predictions of the model to empirical findings.

\footnotetext{
${ }^{7}$ To be precise, the firm is left with $\max (V, 0)$. In the cases that we consider, the value of a vacancy is, however, never negative.

${ }^{8}$ For simplicity, we abstract from flow search costs of firms. Incorporating search costs would not change our qualitative results, though the expressions would become more cumbersome.
} 


\subsection{Wage Inequality}

We refer to wage inequality $\omega$ as the ratio of the wage of a worker with human capital $h(1+\tau)$ to the wage of a worker with human capital $h$, where $\tau>0$. Using equation (8) yields

$$
\omega=\frac{w_{h(1+\tau)}}{w_{h}}=\frac{y_{h(1+\tau)}-r V}{y_{h}-r V}
$$

Proposition 1 Wage inequality increases with the firms' threat point in bargaining.

Proof. Follows directly from (9).

Wages are composed of one part that is proportional to the individual productivity and of another part that is inversely related to the firms' threat point in bargaining, $V$. Ceteris paribus, an increase in the firms' threat point leads to a larger proportional reduction in the wage of workers with lower education levels. Proposition 1 is, however, merely a partial equilibrium result, as it treats the value of a vacancy as an exogenous variable.

We now turn to the determination of the value of a vacancy. We denote the expected average productivity in the economy by $y^{e}$, and the expected productivity in firm $j$ by $y_{j}^{e}$ (Although they coincide in equilibrium, it is nonetheless important to have separate notation because $y^{e}$ is exogenous to the firm.) Denote by $w_{j}^{e}$ the expected wage in firm $j$. Using (3) and (4) we find

$$
r V=\frac{q(\theta)\left(y_{j}^{e}-w_{j}^{e}\right)}{r+\delta+q(\theta)}
$$

In the short run the amount of physical capital and the number of firms is given. Without loss of generality, all firms are assumed to have an identical amount of physical capital $\bar{k}$. Accordingly, the flow of production of a worker with human capital $h$ is given by $y_{h}=h^{\lambda} \bar{k}^{1-\lambda}$. Inserting (8) into (10) and using that all firms are identical yields,

$$
V=\sigma(\theta) y^{e}
$$

where

$$
\sigma(\theta)=\frac{(1-\beta) q(\theta)}{r(r+\delta+(1-\beta) q(\theta)+\beta \theta q(\theta))}
$$

Lemma 1 In the short run $V$ is linear and increasing in $\varepsilon$. 
Proof. Follows directly from (11), from $y^{e}=\bar{k}^{1-\lambda} E\left(h^{\lambda}\right)=\bar{k}^{1-\lambda} \varepsilon$, and from the fact that the number of firms is given, i.e., $\theta=\bar{\theta}$.

Given the sharing rule of the surplus from a match, a firm earns higher profits when employing a better educated (more productive) worker. Hence, when the expected education level of a worker increases, the expected profits from filling a vacancy also increase.

Proposition 2 In the short run an increase in the aggregate education level increases wage inequality.

Proof. Follows immediately from Proposition 1 and Lemma 1.

Proposition 2 is an immediate consequence of the positive relationship between the value of a vacancy and the aggregate education level and of the positive relationship between wage inequality and the firms' threat point in bargaining.

Consider now the long run case where firms choose the level of physical capital, and where there is free entry of firms. As firms invest in physical capital before being matched with a worker, the investment level depends on the distribution of human capital. Consequently, the amount of physical capital is independent of the employed worker's type. Recall that the entire physical capital can be redeployed after separation (Assumption 1).

Let $p k$ denote the cost of physical capital, where $p$ is the price of capital and $k$ is the amount of capital. Free entry implies that the tightness of the labor market $\theta$ is endogenous. Firms enter until the value of a vacant position equals the cost of opening a vacancy, i.e.,

$$
V(\theta, k)=p k
$$

where $V(\theta, k)$ is given by $(11)$.

We now derive the optimal level of physical capital. Inserting the wage equation (6) into (10) gives

$$
r V_{j}=\frac{(1-\beta) q(\theta)\left(y_{j}^{e}(k)-r U^{e}\right)}{r+\delta+(1-\beta) q(\theta)} .
$$

When choosing the physical capital stock, firms take $\theta$ and $r U^{e}$ as given and maximize $V_{j}-p k$. Thus, the resulting optimal capital stock is given by

$$
\frac{\partial V_{j}}{\partial k}=p
$$


This simply means that the marginal cost of capital equals its expected marginal return. Using equation (13) and (12) gives

$$
p k=\Lambda(\theta) y_{j}^{e}
$$

where

$$
\Lambda(\theta)=\frac{(1-\lambda)(1-\beta) q(\theta)}{r(r+\delta+(1-\beta) q(\theta))}
$$

The function $\Lambda(\theta)$ is decreasing in $\theta$. From the above equation it follows that for a given $\theta$ the cost of the physical capital is proportional to $y_{j}^{e}$. Since $V=p k$ in equilibrium, the long run value of a vacancy is also proportional to $y_{j}^{e}$. Solving for $k$ yields

$$
k=\left(\frac{\Lambda(\theta) \varepsilon}{p}\right)^{\frac{1}{\lambda}}
$$

It follows directly that higher aggregate education levels induce firms to invest more for a given $\theta$. Since firms invest prior to being matched, all choose the same amount of physical capital in equilibrium.

Having determined the optimal capital level and hence the long run equilibrium value of a vacancy as a function of $\theta$, we turn to wage inequality. Substituting the free entry condition $V=p k$ and inserting (14) for $p k$ into (9), we obtain

$$
\omega=\frac{w_{h(1+\tau)}}{w_{h}}=\frac{h^{\lambda}(1+\tau)^{\lambda}-r \Lambda(\theta) \varepsilon}{h^{\lambda}-r \Lambda(\theta) \varepsilon}
$$

Proposition 3 In the long run an increase in the aggregate education level increases wage inequality.

Proof. Proposition 3 follows directly from (16) and from the fact that $\theta$ is unique and independent of $F(h)$ (see Appendix B).

A higher education level increases the optimal amount of physical capital, which in turn increases both the productivity of each worker and the value of a vacancy. While the former decreases the wage inequality, the latter increases it. The productivity of each worker is proportional to $k^{1-\lambda}$, while the value of a vacancy (the firm's threat point) is proportional to $k$. Hence, the impact of $k$ through the firm's threat point outweighs the effect through the worker's increased productivity. This implies that wage inequality increases with the level of physical capital. 


\subsection{Real Wages}

Like relative wages, real wages depend in our model on the firms' threat point in bargaining. From equation (8), it is immediate that real wages are decreasing in the value of a vacancy. (Recall that labor market tightness $\theta$ is given in the short run and independent of $F(h)$ in the long run, as shown in Appendix B).

Inserting $V=\sigma(\bar{\theta}) y^{e}$ as defined in equation (11) into equation (8) we obtain the short run wage equation

$$
w_{h}=\frac{r+\delta+\bar{\theta} q(\bar{\theta})}{r+\delta+\beta \bar{\theta} q(\bar{\theta})} \beta\left(h^{\lambda} \bar{k}^{1-\lambda}-r \sigma(\bar{\theta}) y^{e}\right) .
$$

Proposition 4 In the short run the real wage for a given education level $h$ decreases after an increase in the aggregate education level.

Proof. Differentiating (17) with respect to $\varepsilon$ yields

$$
\frac{d w_{h}}{d \varepsilon}=-\frac{r+\delta+\bar{\theta} q(\bar{\theta})}{r+\delta+\beta \bar{\theta} q(\bar{\theta})} \beta r \sigma(\bar{\theta}) \frac{d y^{e}}{d \varepsilon} .
$$

For a fix level of capital $\frac{d y^{e}}{d \varepsilon}>0$ and hence $\frac{d w_{h}}{d \varepsilon}<0$.

Equation (18) implies that an increase in $\varepsilon$ lowers all wages by a quantity which is independent of the workers' education level. This is again due to firms' improved threat point in bargaining.

In the long run the free entry condition $V=p k$ must hold, where $p k=\Lambda(\theta) y^{e}$. Inserted into equation (8), this gives

$$
w_{h}=\frac{r+\delta+\theta q(\theta)}{r+\delta+\beta \theta q(\theta)} \beta\left(h^{\lambda} k^{1-\lambda}-r \Lambda(\theta) y^{e}\right) .
$$

Differentiating with respect to $\varepsilon$ yields ${ }^{9}$

$$
\frac{d w_{h}}{d \varepsilon}=\frac{r+\delta+\theta q(\theta)}{r+\delta+\beta \theta q(\theta)} \frac{\beta}{\varepsilon \lambda}\left((1-\lambda) h^{\lambda} k^{1-\lambda}-r \Lambda(\theta) y^{e}\right) .
$$

The overall effect is ambiguous. On the one hand, the larger amount of physical capital increases wages. On the other hand, the firms' higher threat point decreases wages.

Lemma 2 (i) $\frac{d w_{h}}{d \varepsilon}>0$ for $h>\widehat{h}$ and $\frac{d w_{h}}{d \varepsilon}<0$ for $h<\widehat{h}$, where $\widehat{h}=\left(\frac{r \Lambda(\theta) \varepsilon}{1-\lambda}\right)^{\frac{1}{\lambda}}$

Proof. Follows directly from (19).

In Appendix $\mathrm{C}$ it is shown that $h<\widehat{h}$ is consistent with employability. Under the assumption that $\bar{h}>\widehat{h}>\underline{h}$ we can summarize the long run equilibrium outcomes.

\footnotetext{
${ }^{9}$ First, $\frac{d w_{h}}{d \varepsilon}=\frac{\beta(r+\delta+\theta q(\theta))}{r+\delta+\beta \theta q(\theta)}\left((1-\lambda) h^{\lambda} k^{-\lambda} \frac{\partial k}{\partial \varepsilon}-(1-\lambda) \frac{1}{k} \frac{\partial k}{\partial \varepsilon} r \Lambda(\theta) y^{e}-k^{1-\lambda} r \Lambda(\theta)\right.$. Using equation (15), we find $\frac{\partial k}{\partial \varepsilon}=\frac{k}{\varepsilon \lambda}$, and obtain equation (19).
} 
Proposition 5 In the long run real wages increase for workers with high education levels after an increase in the aggregate education level, while they decrease for those with low levels of education.

Thus, our model is compatible with real wage increases for workers with high education levels and decreases for workers with low education levels. ${ }^{10}$ Notice, however, that the model predicts an increase (decrease) in real wages for all education groups if $\widehat{h}<\underline{h}(\widehat{h}>\bar{h})$.

\subsection{Evolution of relative and real wages in the U.S., Canada, and Europe}

In the absence of firing costs our model predicts that an increase in the supply of highly educated workers leads to an increase in the education premium (both in the short and in the long run). Real wages may also increase for workers with high levels of education, while they decrease for those with low levels.

As discussed in the introduction, the supply of educated workers increased during the 70s and 80s in U.S., Canada, and Europe. The evolution of real and relative wages was, however, markedly different. In terms of relative wages, the U.S., Canada, and the U.K. experienced a large increase in the education premium in the 1980's and 1990's. At the same time the increase was smaller or even negative in many European countries.

Real wages also have followed a different evolution in the these countries. In summary, real wages have increases for workers with high education (wage) levels while they have decreases for those with low education (wage) levels in the U.S. and Canada. In the U.K. real wages have increased for high wage earners while they have been stagnant for low wage earners. In most Continental European countries real wages have increased for all education (wage) groups during the 80 s.

Gottschalk (1997) finds that the weekly earnings of college graduates rose by $5 \%$ in the U.S. during the period 1979 to 1994, while those of high school graduates declined by $20 \%$. Card et al. (1996) find that real wage of male employees declined for most age-education cells between 1979-89 in the U.S.. For Canada, they document a decline for the low wage

\footnotetext{
${ }^{10}$ Explanation based on technological progress are difficult to reconcile with the latter. In the simplest partial equilibrium model, skilled and unskilled workers have to be net-substitutes to generate a decline in real wages of unskilled workers when the productivity of skilled workers increases due to (biased) technical progress, (see e.g. Wasmer (2001)). Krusell et al. (2000) examine the capital-skill complementarity in detail but focus exclusively on the skill premium without discussing real wages.
} 
age-education cells (over the period 1981-88), but an increase for the high wage age-education cells. ${ }^{11}$ They did not find any correlation between the initial wage and the real wage increase in France (between 1982 and 1989). Evidence from other Continental European countries gives a similar picture. Beaudry and Greene (2000) report that real wages increased for German male workers between 1983 and 1996 for virtually all education levels, while in the U.S. real wage declined between 1979 and 1996 for male workers with less than 16 years of schooling (see their Figures 1 and 2). The OECD Job Study (1994) documents that real wages of low paid (and high paid) workers increased during the 80s in Europe. Machin (1996) finds for the period 1978-92 that there was essentially no wage growth for the 10th percentile and that the real wages of the 50th and 90th percentile grew substantially in the U.K..

Overall, the predictions of our model fit the findings about the evolution of relative and real wages in the U.S., Canada and the U.K.. As far as Continental Europe is concerned, additional features need to be added to our model to account for the reported evidence. This is done in the next section.

\section{Firing taxes}

To explain the different evolution of real and relative wages in the U.S. and Europe, we extend our model and introduce an institutional feature which distinguishes these two groups of countries. One such institutional feature often used to explain differences between the U.S. and European labour markets are unemployment benefits. ${ }^{12}$ We consider employment protection legislation instead.

Following Mortensen and Pissarides (1999a), we subsequently restrict attention to firing costs that are not redistributed to workers (as opposed to transfers to workers). We refer to such costs as firing taxes. Transfers to workers tend to be neutral with respect to employment and reduce wages proportionally. By contrast, firing taxes have a much more complex impact, as shown by e.g. Burda (1992), Lazear (1990), and more recently Ljunqvist (2001). Based on the OECD Employment Outlook (1999), Pissarides (2001) summarizes the strictness of employment legislation by a 0-6 index ( 6 being the strictest legislation): The index is 2.5 for

\footnotetext{
${ }^{11}$ The authors have divided the labor force in sub-groups of age and education (age-education cells). They position the labour force on the $\mathrm{x}$-axis according to the initial wage and on the $\mathrm{y}$-axis according to the wage increase. (See their figures 4-6).

${ }^{12}$ Two recent papers relying on this difference are Ljunqvist and Sargent (1998) and Hassler et al.(2001).
} 
the EU, 2.6 for Germany, 2.8 for France, 0.9 for the U.K., 1.1 for Canada, and 0.7 for the US. In addition, Pissarides (2001) defines three types of employment protection which cannot be considered as transfers: Administrative procedures, difficulties of dismissal (challenge by the employee for unfair dismissal, etc...) and additional measures for collective dismissal. These three measures are summarized by an administrative index which equals 2.7 for the EU, 3.4 for Germany, 2.7 for France, 1.0 for the UK, 1.4 for Canada and 0.7 for the U.S.. It seems thus fair to argue that firing costs and firing taxes are higher in Continental European countries than in the U.S., Canada, and the U.K.

We now derive the predictions of the model when firing taxes are taken into account. Denote by $T$ the cost incurred by the firm in case of separation. Furthermore, we assume that firing taxes are indexed on the average productivity in the economy. ${ }^{13}$

Assumption 3: $T=t y^{e}$

Other specifications of firing taxes and transfer costs (severance payments) are discussed in Appendix F. Equation (1), (2), and (3) remain unchanged. The flow value of a position occupied by a worker with human capital $h$ becomes

$$
r J_{h}=h^{\lambda} k^{1-\lambda}-w_{h}+\delta\left[V-T-J_{h}\right]
$$

The firms' threat point in bargaining is now $V-T .{ }^{14}$ The wage of a worker with human capital $h$, is now determined by

$$
\underset{w}{\operatorname{Max}} \Omega(w)=\left(W_{h}-U_{h}\right)^{\beta}\left(J_{h}-V+T\right)^{1-\beta} .
$$

A wage equation is obtained by solving (21), using (2) and (20).

$$
w_{h}=(1-\beta) r U_{h}+\beta\left(h^{\lambda} k^{1-\lambda}-r(V-T)\right)
$$

Inserting the expression for $r U_{h}$ (equation (7)) into (22) gives

$$
w_{h}=\beta \frac{r+\delta+\theta q(\theta)}{r+\delta+\beta \theta q(\theta)}\left(h^{\lambda} k^{1-\lambda}-r(V-T)\right)
$$

\footnotetext{
${ }^{13}$ This assumption ensures that the level of unemployment is independent of the productivity of the workers, which is a desired long-run property of the model. For a discussion of the invariance of the unemployment rate to technology in the long-run, see Layard et al. (1991, ch. 1) and Pissarides (1990, ch. 2).

${ }^{14}$ Mortensen and Pissarides (1999a, 1999b) and Saint-Paul (1995) also use this specification of the firms' threat point.
} 


\subsection{Relative Wages and Firing Taxes}

From equation (23) it follows that wage inequality is now given by

$$
\omega=\frac{w_{h(1+\tau)}}{w_{h}}=\frac{h^{\lambda}(1+\tau)^{\lambda} k^{1-\lambda}-r(V-T)}{h^{\lambda} k^{1-\lambda}-r(V-T)} .
$$

As before, wage inequality increases with the firms' threat point in bargaining. The threat point depends positively on the value of a vacancy. In addition, it is now inversely related to the firing tax.

In the short run the number of jobs (and hence $\theta$ ) and the amount of physical capital is given. For simplicity, all firms are endowed with the same amount of physical capital.

Lemma 3 In the short run higher firing taxes reduce wage inequality.

Proof. The value of a vacancy is equal to (see Appendix D)

$$
V=y^{e} \sigma(t, \theta)
$$

where

$$
\sigma(t, \theta)=\frac{(1-\beta) q(\theta)-q(\theta) t(\beta r+\delta+\beta \theta q(\theta))}{r(r+\delta+(1-\beta) q(\theta)+\beta \theta q(\theta))} .
$$

Note that $\sigma(0, \theta) \equiv \sigma(\theta)$ as defined in Section 3. The value of a vacancy $V$ is proportional to $y^{e}$ and decreasing in $t$. The Lemma follows directly from (24) and the fact that $V$ is decreasing in $t$ for $\theta=\bar{\theta}$ and $k=\bar{k}$.

Higher firing taxes reduce wage inequality through their direct effect on the firm's threat point. In addition, they reduce the value of a vacancy which reinforces the direct effect. Higher firing taxes lower the value of a vacancy because they increase the dead-weight loss associated with exogenous separation and because they lower the firms' threat point in bargaining. To our knowledge, the result that firing taxes reduce wage dispersion has not been explicitly made in the literature.

Using (24), $V=y^{e} \sigma(t, \bar{\theta})$, and $T=t y^{e}$, wage inequality $\omega$ in the short run can be rewritten as

$$
\omega=\frac{h^{\lambda}(1+\tau)^{\lambda}-r(\sigma(t, \bar{\theta})-t) \varepsilon}{h^{\lambda}-r(\sigma(t, \bar{\theta})-t) \varepsilon}
$$

which is increasing in $\varepsilon$ if and only if $\sigma(t, \bar{\theta})>t \Leftrightarrow V>T$.

Proposition 6 In the short run an increase in the aggregate education level reduces wage inequality when firing taxes are high. The reverse holds when firing taxes are low. 
Proof. Follows directly from the above equation.

Given that firing taxes are by assumption proportional to the average productivity, they increase with the workers' education level. Since firing taxes decreases the firm's threat point in the bargaining, the effect of an increase in the supply of highly educated workers on the wage inequality is reduced, or may even be reversed if the firing taxes are sufficiently high.

In the long run firms choose the amount of physical capital $k$, and the free-entry condition $V(\theta, k)=p k$ holds. The expression for $V(\theta, k)$ is given by (25). It can be shown that in equilibrium $p k=\Lambda(\theta) y^{e}$, i.e., the FOC is the same as in the previous section. ${ }^{15}$ Using that $V=p k$, that $p k=\Lambda(\theta) y^{e}$, and that $T=t y^{e}$, equation (24) becomes

$$
\omega=\frac{w_{h(1+\tau)}}{w_{h}}=\frac{h^{\lambda}(1+\tau)^{\lambda} k^{1-\lambda}-r(\Lambda(\theta)-t) y^{e}}{h^{\lambda} k^{1-\lambda}-r(\Lambda(\theta)-t) y^{e}}=\frac{h^{\lambda}(1+\tau)^{\lambda}-r(\Lambda(\theta)-t) \varepsilon}{h^{\lambda}-r(\Lambda(\theta)-t) \varepsilon} .
$$

The wage inequality $\omega$ is a function of $\theta, h, \varepsilon,(\Lambda(\theta)-t)$ and $\tau$.

Proposition 7 In the long run an increase in the aggregate education level reduces wage inequality when firing taxes are high. The reverse holds when firing taxes are low.

Proof. Follows directly from equation (26) and from the fact that $\theta$ is unique and independent of $F(h)$ (see Appendix E).

Even though the firms' threat point depends on firing taxes and on the physical capital stock, the intuition is similar to that of Proposition 3. Consider the case with low firing taxes, i.e., $V-T>0$. As $\varepsilon$ increases, $y^{e}$ increases both directly and through the larger amount of physical capital. Since the threat point $V-T$ is proportional to $y^{e}$ and positive, it increases with the educational level $\varepsilon$. Ceteris paribus, this implies that wage inequality increases. There is, however, a counterveiling effect. When the education level increases, workers become more productive due to higher $k$, which lowers wage inequality ceteris paribus. The productivity of each worker is proportional to $k^{1-\lambda}$, while the threat point is proportional to $y^{e}=\varepsilon k^{1-\lambda}$. This implies that the effect of an increase in $\varepsilon$ on the threat point (through $\varepsilon$ directly and $k$ ) outweights the effect of the workers' increased productivity. Hence, for low firing taxes an increase in the educational level increases inequality. By contrast, when firing taxes are high, i.e. $V-T<0$, both the effect on productivity and on the firms' threat point mitigate wage inequality. Consequently, an increase in the education level decreases wage inequality when firing taxes are high.

\footnotetext{
${ }^{15}$ Use equation (22) and (29) in appendix and note that firing costs are exogenous to the firm.
} 
In summary, our model with firing taxes predicts that an increase in the education level increases wage inequality when firing costs are low, while the reverse holds when firing costs are high. These results fit well with the different evolution of relative wages in Continental Europe versus the U.S., the U.K., and Canada.

In addition, the introduction of firing taxes allows us to relate wage inequality to job creation and destruction costs. Since $V$ is equal to the creation costs of a vacancy $p k$ and since $T$ is the destruction costs, changes in wage inequality following an increase in the educational level are a positive function of the difference between creation and destruction costs.

\subsection{Real Wages and Firing Taxes}

The derivation of real wages with firing taxes is immediate from the previous analysis. In all expressions for wages $\sigma(\theta)$ is replaced by $\sigma(t, \theta)-t$ in the short-run, and $\Lambda(\theta)$ is replaced by $\Lambda(\theta)-t$ in the long run.

Proposition 8 In the short run an increase in the aggregate education level increases real wages for a given education level when firing taxes are high. The reverse holds when firing taxes are low.

Proof. Differentiating (23) with respect to $\varepsilon$, and using that $V=y^{e} \sigma(t, \bar{\theta}), k=\bar{k}$ and $T=t y^{e}$ yields

$$
\frac{d w_{h}}{d \varepsilon}=-\frac{r+\delta+\theta q(\theta)}{r+\delta+\beta \theta q(\theta)} \beta r(\sigma(t, \bar{\theta})-t) \frac{d y^{e}}{d \varepsilon}
$$

Hence $\frac{d w_{h}}{d \varepsilon}<0$ if $\sigma(t, \bar{\theta})-t>0$ and $\frac{d w_{h}}{d \varepsilon}>0$ if $\sigma(t, \bar{\theta})-t<0$.

When firing taxes are low, the firms' threat point in the bargaining increases, and the wage for a given education level decreases after an increase in $\varepsilon$. The reverse holds when firing taxes are high.

The long-run impact of a higher $\varepsilon$ on real wages is found by differentiating equation (23) and using $V=\Lambda(\theta) y^{e}{ }^{16}$

$$
\frac{d w_{h}}{d \varepsilon}=\frac{r+\delta+\theta q(\theta)}{r+\delta+\beta \theta q(\theta)} \frac{\beta}{\varepsilon \lambda}\left((1-\lambda) h^{\lambda} k^{1-\lambda}-r(\Lambda(\theta)-t) y^{e}\right) .
$$

When firing costs exceed the value of a vacancy (i.e. $(\Lambda(\theta)-t)<0$ ), wages increase with the education level, because each worker's productivity increases (due to an increase in $k$ ), and

\footnotetext{
${ }^{16}$ The algebra is analogous to that in section 3.2 .
} 
because the firms' threat point decreases. When the value of a vacancy exceeds the firing costs (i.e. $(\Lambda(\theta)-t)>0$ ), the effect on real wages is ambiguous. The larger amount of physical capital increases wages, but the firms' higher threat point decreases wages. Analogous to Lemma 2 we have the following result.

Lemma 4 : (i) When $\Lambda(\theta)-t>0 \frac{d w_{h}}{d \varepsilon}>0$ for $h>\widehat{h}(t)$ and $\frac{d w_{h}}{d \varepsilon}<0$ for $h<\widehat{h}(t)$, where $\widehat{h}(t)=\left(\frac{r(\Lambda(\theta)-t) \varepsilon}{1-\lambda}\right)^{\frac{1}{\lambda}}$.

Proof. Follows directly from (27).

Under the assumption that $\bar{h}>\widehat{h}>\underline{h}$ we can summarize the long run equilibrium outcomes.

Proposition 9 In the long run an increase in the aggregate education level increases real wages for workers of all education levels when firing taxes are high. When firing taxes are low real wages increase for workers with high education levels but decrease for workers with low education levels.

The impact of an increase in education depends on the size of the firing taxes. If firing taxes are high real wages increase for all workers. If firing taxes are low and $\bar{h}>\widehat{h}>\underline{h}$ the wages of workers with low education levels decrease but the wages of highly educated workers increase. $^{17}$

Our model thus fits well the Continental European evolution of real wages, as well as the divergence from the experience in the U.S., Canada and the U.K. due to differences in job protection.

\section{Robustness and generalization}

Here we examine to what extent our results rely on the assumptions regarding firing costs and full redeployability of physical capital (zero replacement cost). Our results hold under alternative specifications of both the firing costs and replacement costs. In addition, these robustness checks show that the impact of costs differ with the cause of separation and that changes in wage inequality following an increase in the aggregate education level depends on the relation between job creation and job destruction costs.

\footnotetext{
${ }^{17}$ Analogous to section 3 the model with firing taxes predicts an increase (decrease) in real wages for all educational groups if $\widehat{h}<\underline{h}(\widehat{h}>\bar{h})$.
} 
Consider a modified version of the model in which part of the physical capital has to be replaced when firm and worker separate and in which the size of both replacement costs and firing taxes depend on the cause of separation. Denote by $R_{\delta}$ replacement cost after an exogenous job destruction ( $\delta$-separation) and by $R_{\beta}$ the replacement cost after separation during bargaining ( $\beta$-separation). Although $\beta$-separations never occur in equilibrium we have to consider them to determine the firm's threat point. Let $T_{\beta}$ denote the firing taxes in case of a $\beta$-separation and $T_{\delta}$ the firing taxes in case of a $\delta$-separation. Both firing taxes are assumed to be proportional to $y^{e}$. Thus, the framework of section 4 is a special case of the present one, with $R_{\delta}=R_{\beta}=0$ and $T_{\delta}=T_{\beta}$.

The modified equations for real wages and wage inequality are then given by (see Appendix F)

$$
w_{h}=\frac{r+\delta+\theta q(\theta)}{r+\delta+\beta \theta q(\theta)} \beta\left(h^{\lambda} k^{1-\lambda}-r V+r \Xi\right)
$$

and

$$
\omega_{\tau}=\frac{h^{\lambda} k^{1-\lambda}(1+\tau)-r(V-\Xi)}{h^{\lambda} k^{1-\lambda}-r(V-\Xi)}
$$

where

$$
r \Xi=(r+\delta)\left(R_{\beta}+T_{\beta}\right)-\delta\left(R_{\delta}+T_{\delta}\right)
$$

The above equations show that the impact of replacement costs and firing taxes depends on the cause for separation.

Proposition 10 In the short run costs associated with $\beta$-separations $\left(T_{\beta}\right.$ and $\left.R_{\beta}\right)$ increase real wages and reduce wage inequality, while the reverse holds for costs associated with $\delta$ separations $\left(R_{\delta}\right.$ and $\left.T_{\delta}\right)$.

Proof. It follows directly from above equations.

Ceteris paribus, costs associated with $\beta$-separations $\left(T_{\beta}\right.$ and $\left.R_{\beta}\right)$ increase real wages and reduce wage inequality because the firm's threat point is now $V-R_{\beta}-T_{\beta}$. By contrast, costs associated with $\delta$-separations decrease real wages and increase wage inequality: They reduce the value of a match $J_{h}$ and this reduction is independent of worker's education level h. Ljunqvist (2001) provides a detailed analysis of the role of firing costs for the labour market outcome. Allowing for cause-specific firing costs, the above result adds to his analysis and further clarifies the impact of firing costs.

As regards changes in relative wages following an increase in the aggregate education level $\varepsilon$, appendix $\mathrm{F}$ shows that our previous results also obtain in this more general setting. In 
particular, an increase in $\varepsilon$ raises wage inequality in the long run to the extent that $V=p k$ exceeds $\Xi$. In appendix $\mathrm{F}$ we also discuss the robustness of our results with respect to the assumption that firing costs are not redistributed to workers and that they are proportional to the average productivity in the ecomomy $y^{e}$.

Finally, consider the case where $R_{\beta}=R_{\delta}=R$ and $T_{\beta}=T_{\delta}=T$, which implies that $\Xi=T+R$. In the long run changes in wage inequality following an increase in the aggregate education level are then a positive function of the difference between job creation costs $p k$ and job destruction $\operatorname{costs} T$ and $R$. This confirms our result at the end of section 4.1 in a more general setting.

\section{Concluding comments}

Most of the literature explains the U.S. experience of simultaneous increases in the education premium and in the supply of highly educated workers in a conventional labour demand/labour supply framework augmented with skill-biased technological changes. Like the more recent papers cited in introduction, we offer a complementary explanation based on the existence of search frictions. Our mechanism is, however, novel and operates through changes in the firms' bargaining position following an increase in the supply of highly educated workers. A key insight of the model is that (keeping firing taxes constant) higher overall education of workers produces positive wage effects through higher capital accumulation and negative wage effects through the firms' higher outside options in bargaining. The latter affects all workers in the same way, whereas the former affects more the highly skilled workers due to the skill/capital complementarity. As a result, higher education results in higher inequality between skilled workers and unskilled workers. Like skill-biased explanations our theory is consistent with the observed increase in real wages for highly educated workers in the U.S. Our theory can also account for lower real wages of the less educated workers. Based on different firing costs we provide an explanation for the diverging wage development in Continental Europe.

A primary objective of this paper is to analyse the impact of an increase in the supply of highly educated workers on inequality and real wages. Therefore, we have treated changes in education levels as exogenous to the labour market outcome. Allowing also for a (causal) relationship between wage levels and supply of educated workers would make for a richer analysis, including the possibility of multiple equilibira. We leave such a generalization for 
future research. Nonetheless, an increase in the education level may in part be viewed as exogeneous to the labour market outcome. For instance, if education is a normal good, richer cohorts will consume more education than poorer cohorts and increasing living standards may be the rationale for the growing numbers of highly educated workers in OECD labour markets.

Although testing our theory and its mechanism is beyond the scope of this paper, we would like to suggest two possible approaches. One approach is to test how changes in cross country wage inequality depend on improvements in the workers' education level and on differences in employment protection. This can be considered a test of the reduced form of the model. Another approach aims at testing the mechanism of our theory more directly. Using firm level data, one can examine how wages depend on the determinants of the firms' outside option, i.e., on replacement and separation costs and on the availability and the quality of alternative workers.

\section{References}

[1] Abraham, K. G. and Houseman, S. N. (1995), "Earnings Inequality in Germany" in Differences and changes in wage structures, in R. Freeman and L. Katz (eds.), Differences and Changes in Wage Structure, Chicago, University of Chicago Press.

[2] Acemoglu, D. (1996), "A Microfoundation for Social Increasing Returns in Human Capital Accumulation" Quarterly Journal of Economics, 111, 779-804.

[3] Acemoglu, D. (1997), "Matching, Heterogeneity, and the Evolution of Income Distribution" Journal of Economics Growth, 2, 61-92.

[4] Acemoglu, D. (1999), "Changes in Unemployment and Wage Inequality: An Alternative Theory and some Evidence" American Economic Review, 89, 1259-1278.

[5] Albrecht, J. and Vroman, S. (1999) "A Matching Model with Endogenous Skill Requirements" Georgetown University, mimeo.

[6] Beaudry, P. and Green, D. (1998), "What is Driving U.S. and Canadian Wages: Exogenous Technical Change or Endogenous Choice of Thechnique?" NBER Working paper 6853.

[7] Beaudry, P. and Green, D. (2000), "Wages and Employment in the US and Germany: What Explains the Difference", mimeo, Concordia.

[8] Berman, E., Bound J. and Griliches, Z. (1994), "Changes in the Demand for Skilled Labor Within U.S. Manufacturing Industries: Evidence from the Annual Survey of Manufacturing" Quarterly Journal of Economics, 109, 367-398.

[9] Bertola, G. (1990), "Job Security, Employment and Wages" European Economic Review, 34, 851-886. 
[10] Blanchard, O.J (1997), "Labor Market Flexibility and Aggregate Employment Volatility" Carnegie Rochester Conference Series on Public Policy, 46, 229-239.

[11] Bound, J., and Johnson, G. (1992), "Changes in the Structure of Wages in the 1980:s: An Evaluation of Alternative Explanations" American Economic Review, 82, 371-392.

[12] Burda, M. (1992), "A Note on Firing Costs and Severance Benefits in Equilibrium Unemployment" Scandinavian Journal of Economics, 94, 479-89.

[13] Card, D., Kramarz, F. and Lemieux, T. (1996), "Changes in the Relative Structure of Wages and Employment: A Comparison of the United States, Canada and France" NBER Working Paper, No. 5487.

[14] Caroli, E. and Van Reenen, J. (1999), "Organization, skills and technology: evidence from a panel of British and French establishments" Institute for Fiscal Studies, W99/23.

[15] Davis, S.J. (1992), "Cross-Country Patterns of Changes in Relative Wages" NBER Macroeconomic Annual, 7, 239-300.

[16] DiNardo, J., Fortin, N.M., and Lemieux, T. (1996), "Labor Marker Institutions and the Distributions of Wages, 1973-1992: A Semiparametric Approach" Econometrica, 64, 1001-1044.

[17] Duranton G. (1997), "The Economics of Productive Systems: Segmentation and SkillBiased Change" London School of Economics, mimeo.

[18] Gottschalk, P. (1997), "Inequality in Income, Growth and Mobility: The Basic Facts" Journal of Economic Perpspectives, 11, 21-40.

[19] Hassler, J., Storesletten, K., Rodriguez Mora, J. V. and Zilibotti, F. (2001), "A Positive Theory of Geographic Mobility and Social Insurance" CEPR discussion paper no. 2964.

[20] June, C., Murphy, K. and Pierce, B. (1993), "Wage Inequality and the Rise in Returns to Skill" Journal of Political Economy, 101, 410-442.

[21] Katz, L., Loveman, G. and Blanchflower, D. (1995), "A Comparison of Changes in the Structure of Wages in Four OECD Countries" in R. Freeman and L. Katz (eds.), Differences and Changes in Wage Structure, Chicago: University of Chicago Press.

[22] Katz, L. and Murphy, K. (1992), "Changes in relative wages, 1963- 1987: Supply and demand factors" Quarterly Journal of Economics, 107, 35-78.

[23] Krussel, P. Ohanian L.E., Rios-Rull, J.V., Violante, G.L. (2000), "Capital-Skill Complementarity and Inequality : A Macroeconomic Analysis" Econometrica, 68, 1029-1053.

[24] Layard, R., Nickell, S. and Jackman, R. (1991), Unemployment: Macroeconomic Performance and the Labour Market, Oxford, Oxford University Press.

[25] Lazear E. P. (1990), "Job Security Provisions and Employment" Quarterly Journal of Economics, 105, 699-726.

[26] Lee, D. S. (1999), "Wage Inequality in The United States During the 1980s: Rising Dispersion or Falling Minimum Wage" Quarterly Journal of Economics, 114, 977-1023. 
[27] Levy, F. and Murname, R. (1992), "U.S. Earnings Levels and Earnings Inequality: A Review of Recent Trends and Proposed Explanations" Journal of Economic Literature, 30, 1333-81.

[28] Ljunqvist, L. (2001), "How Do Layoff Costs Affect Employment?" Stockholm School of Economics, mimeo.

[29] Ljunqvist, L. and Sargent, T.J. (1998), "The European Unemployment Dilemma" Journal of Political Economy, 106, 514-550.

[30] Machin, S. (1996), "Wage Inequality in the UK" Oxford Review of Economic Policy, 12, 47-64.

[31] Machin, S. and Manning, A. (1997), "Can Supply Create its own Demand? Implications for Rising Skill Differentials", European Economic Review, Papers and Proceedings, 41, $507-16$.

[32] Machin, S. and Van Reenen, J. (1998), "Technology and Changes in Skill Structure: Evidence from Seven OECD Countries" Quarterly Journal of Economics, 113, 12151244.

[33] Mortensen, D.T. and Pissarides, C.A. (1999a), "Job Reallocation, Employment Fluctuations and Unemployment", in J.B. Taylor and M. Woodford (eds), Handbook of Macroeconomics, 1b, North-Holland, 1171-1228.

[34] Mortensen, D.T. and Pissarides, C.A. (1999b), "Unemployment Responses to "SkillBiased" Technology Shocks: The Role of Labor Market Policy" The Economic Journal, 109, 242-265.

[35] Nickell, S., and Bell, B. (1995), "The Collaps in Demand for the Unskilled and Unemployment Across the OECD" Oxford Review of Economic Policy, 11, 40-62.

[36] Organization for Economic Cooperation and Development (1994), Job Study, Paris, OECD.

[37] Organization for Economic Cooperation and Development (1999), Employment Protection and Labor Market Performance, Employment Outlook, Paris, OECD.

[38] Pissarides, C.A. (1990), Equilibrium Unemployment Theory, Basil Blackwell, Cambridge MA.

[39] Pissarides, C.A. (2000), Equilibrium Unemployment Theory, 2nd edn. MIT Press, Cambridge MA.

[40] Pissarides, C.A. (2001), "Employment Protection" Labour Economics, 8, 131-159.

[41] Rioux, L. (1995), "Heterogeneity, Matching, and Endogenous Labor Market Segmentation" DELTA, mimeo.

[42] Saint-Paul, G. (1995), "The High Unemployment Trap" Quarterly Journal of Economics, $110,527-550$.

[43] Wasmer, E. (2001), "Between-group competition in the labor market and the rising returns to skill. US and France 1964-2000" CEPR discussion paper 2798. 
[44] Wood, A. (1994), North-South Trade, Employment and Inequality, Oxford: Claredon Press. 


\section{APPENDIX}

\section{A Employability}

A match results in employment if and only if $U_{h}<W_{h}$ and $V<J_{h}$. Given Nash-bargaining, this implies that a worker is employable if and only if $U_{h}+V<W_{h}+J_{h}$. Using (1), (2), (4) and (7) this condition is equivalent to

$$
r V<y_{h}
$$

Inserting the expression for $r V$ (equation (11)) yields

$$
\frac{(1-\beta) q(\theta) y^{e}}{r+\delta+(1-\beta) q(\theta)+\beta \theta q(\theta)}<y_{h}
$$

The condition for employability is thus

$$
\frac{(1-\beta) q(\theta) E\left(h^{\lambda}\right)}{r+\delta+(1-\beta) q(\theta)+\beta \theta q(\theta)}<\underline{h}^{\lambda} .
$$

\section{B Proof of Proposition 3}

Using (11) and (14),

$$
V=p k<=>\frac{(1-\beta) q(\theta) y^{e}}{r(r+\delta+(1-\beta) q(\theta)+\beta \theta q(\theta))}=\frac{(1-\lambda)(1-\beta) q(\theta) y^{e}}{r(r+\delta+(1-\beta) q(\theta))} .
$$

$<=>$

$$
\frac{r+\delta+(1-\beta) q(\theta)}{r+\delta+(1-\beta) q(\theta)+\beta \theta q(\theta)}-(1-\lambda)=0 .
$$

From (28) it follows that $\theta$ is independent of $F(h)$.

Let $B(\theta)$ denote the left hand side of (28). Taking the derivative of $B(\theta)$ with respect to $\theta$ gives

$$
\frac{d B(\theta)}{d \theta}=\frac{\frac{d q(\theta)}{d \theta}(1-\beta) \beta \theta q(\theta)-\beta \frac{d \theta q(\theta)}{d \theta}(r+\delta+(1-\beta) q(\theta))}{(r+\delta+(1-\beta) q(\theta)+\beta \theta q(\theta))^{2}} .
$$

Since $\frac{d q(\theta)}{d \theta}<0$ and $\frac{d \theta q(\theta)}{d \theta}>0$, it follows that $\frac{d B(\theta)}{d \theta}<0$. As $B(\theta)$ is continuous in all its arguments, it follows from $\frac{d B(\theta)}{d \theta}<0$ that the solution to $B(\theta)=0$ is unique.

\section{Proof of that $\mathbf{h}<\hat{\mathbf{h}}$ is consistent with employability}

A worker is employable if and only if

$$
h^{\lambda} k^{1-\lambda}-r V \geqslant 0
$$

Using $V=\Lambda(\theta) y^{e}$ yields

$$
h^{\lambda}+r \Lambda(\theta) \varepsilon \geqslant 0 .
$$

Let $h_{\min }$ denote the lowest level of $h$ at which a worker is still employable. It follows that

$$
h_{\min }=(r \Lambda(\theta) \varepsilon)^{\frac{1}{\lambda}} .
$$


Using equation (27), the cut-off $\widehat{h}$ is defined by

$$
\widehat{h}=\left(\frac{r \Lambda(\theta) \varepsilon}{1-\lambda}\right)^{\frac{1}{\lambda}}
$$

and hence $h_{\min }<\widehat{h}$.

\section{Proof of Lemma 3}

Using (3), (20) and Assumption 3 gives

$$
r V=\frac{q(\theta) E\left(h^{\lambda} k^{1-\lambda}-w_{h}-\delta t y^{e}\right)}{r+\delta+q(\theta)} .
$$

Given that all firms have the same level of $k$, inserting (23) into (29) gives

$$
V=y^{e} \sigma(t, \theta)
$$

where

$$
\sigma(t, \theta)=\frac{(1-\beta) q(\theta)-q(\theta) t(\beta r+\delta+\beta \theta q(\theta))}{r(r+\delta+(1-\beta) q(\theta)+\beta \theta q(\theta))} .
$$

Hence Lemma 3 follows.

\section{E $\quad$ Proof of Proposition 7}

From equations (14) and (25), and $V=p k$ follows that the equilibrium $\theta$ is defined by

$$
\frac{(1-\beta) q(\theta)-q(\theta) t(\beta r+\delta+\beta \theta q(\theta))}{r+\delta+(1-\beta) q(\theta)+\beta \theta q(\theta)}=\frac{(1-\lambda)(1-\beta) q(\theta)}{r+\delta+(1-\beta) q(\theta)}
$$

It is immediate that $\theta$ is independent of $\varepsilon$. Below we show that (30) defines $\theta$ uniquely. Equation (30) can be rewritten as

$$
\frac{r+\delta+(1-\beta) q(\theta)}{r+\delta+(1-\beta) q(\theta)+\beta \theta q(\theta)}(1-t(\beta r+\delta+\beta \theta q(\theta)))-(1-\lambda)=0
$$

Let $B(\theta)$ denote the left hand side of the above equation. Taking the derivative of $B(\theta)$ with respect to $\theta$ gives

$$
\begin{aligned}
\frac{d B(\theta)}{d \theta}= & \frac{\frac{d q(\theta)}{d \theta}(1-\beta) \beta \theta q(\theta)-\beta \frac{d \theta q(\theta)}{d \theta}(r+\delta+(1-\beta) q(\theta))}{(r+\delta+(1-\beta) q(\theta)+\beta \theta q(\theta))^{2}}(1-t(\beta r+\beta \theta q(\theta)+\delta)) \\
& -t \beta \frac{r+\delta+(1-\beta) q(\theta)}{r+\delta+(1-\beta) q(\theta)+\beta \theta q(\theta)} \frac{d \theta q(\theta)}{d \theta}
\end{aligned}
$$

Since $\frac{d q(\theta)}{d \theta}<0, \frac{d \theta q(\theta)}{d \theta}>0$, and $1-t(\beta r+\beta \theta q(\theta)+\delta)>0$ at $B(\theta)=0$, it follows that $\frac{d B(\theta)}{d \theta}<0$ at $B(\theta)=0$. As $B(\theta)$ is continuous in all its arguments it follows from $\frac{d B(\theta)}{d \theta}<0$ at $B(\theta)=0$, that the solution to $B(\theta)=0$ is unique. 


\section{F Robustness}

First, we analyze the case where the firing taxes depend on the cause of separation and where part of the physical capital has to be replaced after a separation. Let $T_{\beta}$ denote the firing taxes in case of separation during wage bargaining $\left(\beta\right.$-separation) and $T_{\delta}$ the firing taxes in case of an exogenous destruction ( $\delta$-separation). Both taxes are again assumed to be proportional to $y^{e}$.

Assumption 4: $T_{\beta}=t_{\beta} y^{e}$ and $T_{\delta}=t_{\delta} y^{e}$

As before, the physical capital costs $p k$ have to be paid when opening a new vacancy. In addition, a fraction of the capital has to be replaced before opening the position after a separation. The replacement cost in case of a $\beta$-separation is $R_{\beta}$, and in case of an $\delta$-separation $R_{\delta}$, where $R_{\beta}=\rho_{\beta} p k$ and $R_{\delta}=\rho_{\delta} p k$. We further assume that $\rho_{\beta}<1$ and $\rho_{\beta} \leq \rho_{\delta}$. These assumptions capture the idea that physical capital has some value, even if the worker leaves during wage bargaining, and that a larger fraction has to be replaced after an exogenous shock.

Equation (1), (2), and (3) remain unchanged. The flow value of a position occupied by a worker with human capital $h$ becomes

$$
r J_{h}=h^{\lambda} k^{1-\lambda}-w_{h}+\delta\left(V-R_{\delta}-T_{\delta}-J_{h}\right) .
$$

The firms' threat point in wage bargaining is now $V-R_{\beta}-T_{\beta}$. Hence, the wage of a worker with human capital $h$ is determined by

$$
\underset{w}{\operatorname{Max}} \Omega(w)=\left(W_{h}-U_{h}\right)^{\beta}\left(J_{h}-V+R_{\beta}+T_{\beta}\right)^{1-\beta} .
$$

A wage equation is obtained by solving (32) and using (2) and (31)

$$
w_{h}=(1-\beta) r U_{h}+\beta\left[h^{\lambda} k^{1-\lambda}-r V+(r+\delta)\left(R_{\beta}+T_{\beta}\right)-\delta\left(R_{\delta}+T_{\delta}\right)\right] .
$$

Inserting the expression for $r U_{h}$ (equation (7)) into (33) yields

$$
w_{h}=\frac{r+\delta+\theta q(\theta)}{r+\delta+\beta \theta q(\theta)} \beta\left(h^{\lambda} k^{1-\lambda}-r V+(r+\delta)\left(R_{\beta}+T_{\beta}\right)-\delta\left(R_{\delta}+T_{\delta}\right)\right) .
$$

Wage inequality becomes

$$
\omega_{\tau}=\frac{h^{\lambda} k^{1-\lambda}(1+\tau)^{\lambda}-r(V-\Xi)}{h^{\lambda} k^{1-\lambda}-r(V-\Xi)}
$$

where

$$
r \Xi=(r+\delta)\left(R_{\beta}+T_{\beta}\right)-\delta\left(R_{\delta}+T_{\delta}\right) .
$$

Costs associated with a $\beta$-separation $\left(T_{\beta}\right.$ and $\left.R_{\beta}\right)$ decrease the firms' threat point and thereby decreases wage inequality ceteris paribus. By contrast, costs associated with a $\delta$-separation $\left(T_{\delta}\right.$ and $R_{\delta}$ ) tend to increase inequality. They decrease the total surplus of a match by an amount that is independent of the productivity of the worker.

Proposition 11 In the short run an increase in the aggregate education level increases wage inequality if $t_{\beta}$ is low, but decreases wage inequality if $t_{\beta}$ is high and $t_{\delta}$ is low.

Proof. Using (3) and (31) yields

$$
r V=\frac{q(\bar{\theta}) E\left(h^{\lambda} k^{1-\lambda}-w_{h}-\delta\left(R_{\delta}+T_{\delta}\right)\right)}{r+\delta+q(\bar{\theta})} .
$$


Inserting the expression for $w_{h}$ (equation (34)), $T_{\delta}=t_{\delta} y^{e}$, and $T_{\beta}=t_{\beta} y^{e}$ gives

$$
r V=\frac{q(\bar{\theta})\left((1-\beta) y^{e}-(1-\beta) \delta\left(R_{\delta}+t_{\delta} y^{e}\right)-(r+\delta+\bar{\theta} q(\bar{\theta})) \beta\left(R_{\beta}+t_{\beta} y^{e}\right)\right)}{r+\delta+q(\bar{\theta})(1-\beta)+\beta \bar{\theta} q(\bar{\theta})} .
$$

Taking the derivative of $r V$ with respect to $\varepsilon$ gives

$$
\frac{d r V}{d \varepsilon}=\frac{q(\bar{\theta})\left((1-\beta)-(1-\beta) \delta t_{\delta}-(r+\delta+\bar{\theta} q(\bar{\theta})) \beta t_{\beta}\right)}{r+\delta+q(\bar{\theta})(1-\beta)+\beta \bar{\theta} q(\bar{\theta})} \frac{d y^{e}}{d \varepsilon} .
$$

Using equation (36),

$$
\frac{d \Xi}{d \varepsilon}=\left((r+\delta) t_{\beta}-\delta t_{\delta}\right) \frac{d y^{e}}{d \varepsilon}
$$

Hence,

$$
\begin{gathered}
\frac{d(V-\Xi)}{d \varepsilon} \gtreqless 0<=> \\
q(\bar{\theta})(1-\beta)+t_{\delta}(r+\delta+\beta \bar{\theta} q(\bar{\theta}))-t_{\beta}((r+\delta)(r+\delta+q(\bar{\theta})+\beta \bar{\theta} q(\bar{\theta}))+\beta q(\bar{\theta}) \bar{\theta} q(\bar{\theta})) \gtreqless 0 .
\end{gathered}
$$

Thus, $\frac{d(V-\Xi)}{d \varepsilon}>0$ for low values of $t_{\beta}$, and $\frac{d(V-\Xi)}{d \varepsilon}<0$ for high values of $t_{\beta}$ and low values of $t_{\delta}$.

For low values of $t_{\beta}, V-\Xi$ increases with $\varepsilon$, and hence inequality increases. For high values of $t_{\beta}$ and low values of $t_{\delta}, V-\Xi$ is more likely to decrease following an increase in the education level.

In the long run, where is free entry and firms choose the amount of physical capital.

Proposition 12 In the long run an increase in the aggregate education level increases the education premium if and only if $V-\Xi$ is positive.

Proof. Here we only give an outline of the proof which is available on request. Similarly to the proof of proposition 7, it can be shown that $\theta$ unique and independent of $\varepsilon$ and that $V$ is proportional to $y^{e}$. Since $\Xi$ also is proportional to $y^{e}$, and $y^{e}=\varepsilon k^{1-\lambda}$, the proposition follows directly from differentiating (35) with respect to $\varepsilon$.

Propositions 11 and 12 show that our inequality results are robust to both changes in the specifications of the firing taxes and to the introduction of replacement costs. Moreover, we have shown that firing taxes due to disagreement and due to destruction affect inequality differently.

As regards changes in real wages following an increase in $\varepsilon$ we conjecture that Propositions $4,5,8$, and 9 are robust to the above generalization. In the long run an increase in $\varepsilon$ will have an ambiguous effect on real wages if $V-\Xi>0$ and otherwise increase real wages for all levels of human capital.

Next we discuss the robustness of the results with respect to other variations of the model. Formal proofs are available on request. It can be shown that none of our results would change if firing taxes were proportional to the average wage in the economy. This is because the average wage is proportional to the average productivity. Our results also hold when firing taxes are indexed on the average productivity in the firm, rather than the average productivity in the whole economy. If firing taxes are proportional to the current wage, i.e., depend on the education level of the worker, they do not affect inequality directly. The expression for wage inequality coincides with the one presented in section 3. Hence, changes in wage inequality following a change in $\varepsilon$ have the same sign as in section 3. Changes in the real wage in response to a change in $\varepsilon$ have the same sign as in the case with low firing taxes. Similarly, if firing costs were to be redistributed to workers (e.g., severance payments), they would not affect wage inequality directly. When severance payments are indexed on the average productivity, clear cut results are difficult to derive without specifying an explicit form of the matching function. This case seems, however, less relevant as severance payment are typically indexed on the previous wages. 